\title{
CO-MORBIDITY BETWEEN MAJOR DEPRESSION AND SCHIZOPHRENIA: PREVALENCE AND CLINICAL CHARACTERISTICS
}

\author{
Abdulbari Bener ${ }^{1,2}$, Elnour E. Dafeeah ${ }^{3}$, Mohammed T. Abou-Saleh ${ }^{4}$, \\ Dinesh Bhugra $^{5}$ \& Antonio Ventriglio ${ }^{6}$ \\ ${ }^{I}$ Department of Biostatistics \& Medical Informatics, Cerrahpaşa Faculty of Medicine Istanbul University, \\ Istanbul, Turkey \\ ${ }^{2}$ Department of Evidence for Population Health Unit, School of Epidemiology and Health Sciences, \\ University of Manchester, Manchester, UK \\ ${ }^{3}$ Department of Psychiatry, Rumeilah Hospital, Hamad Medical Corporation, Doha, Qatar \\ ${ }^{4}$ Addiction Research Group, Division of Mental Health, St George's University of London, Cranmer Terrace, \\ London, UK \\ ${ }^{5}$ Department of Psychiatry, HSPRD, Institute of Psychiatry, King's College London, London, UK \\ ${ }^{6}$ Deptartment of Clinical \& Experimental Medicine, University of Foggia, Foggia, Italy
}

received: 7.11.2019;

revised: 14.2.2020;

accepted: 27.3 .2020

\section{SUMMARY}

Backround: The aim of this study was to explore the co-morbidity between Major Depressive Disorder (MDD) and Schizophrenia (SZ) among a large number of patients describing their clinical characteristics and rate of prevalence.

Subjects and methods: A cohort-study was carried out on 396 patients affected by MDD and SZ who consecutively attended the Department of Psychiatry, Rumeilah Hospital in Qatar. We employed the World Health Organization - Composite International Diagnostic Interview (WHO-CIDI) and the Structured Clinical Interview for DSM-5 (SCID-5) for diagnoses. Patients were also grouped in MDD patients with and without co-morbid SZ (MDD vs MDD/SZ) for comparisons.

Results: A total of 396 subjects were interviewed. MDD patients with comorbid SZ (146(36.8\%)) were $42.69 \pm 14.33$ years old

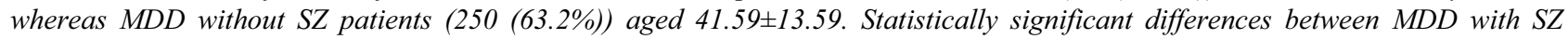
patients and MDD without SZ patients were: higher BMI (Body Mass Index) ( $p=0.025)$, lower family income ( $p=0.004)$, higher rate of cigarette smoking $(p<0.001)$, and higher level of consanguinity $(p=0.023)$. Also, statistically significant differences were found in General Health Score ( $p=0.017)$, Clinical Global Impression-BD Score ( $p=0.042)$, duration of illnesses $(p=0.003)$, and Global Assessment of Functioning ( $p=0.012)$. Rates of anxiety dimensions (e.g.: general anxiety, agoraphobia, somatisation, etc.), mood dimensions (e.g.: major depression, mania, oppositional defiant behaviour, Bipolar disorder), Attention Deficit Hyperactivity Disorder, psychotic and personality dimensions were higher among MDD with SZ patients than MDD without SZ.

Conclusion: This study confirms that MDD with $S Z$ is a common comorbidity especially among patients reporting higher level of consanguinity. MDD/SZ comorbidity presents unfavourable clinical characteristics and higher levels of morbidity at rating scales.

Key words: schizophrenia - major depressive disorder - co-morbidity - consanguinity

$$
* * * * *
$$

\section{INTRODUCTION}

Patients reporting comorbidity between Major Depressive Disorder (MDD) and Schizophrenia (SZ) may represent a specific diagnostic category requiring specific treatments (Moller 2008, Bartels \& Drake 1988). Also, detecting MDD symptoms among patients with Schizophrenia or psychotic symptoms among MDD patients may be especially important in order to consider appropriate treatments beyond mood and psychotic symptoms (Knights \& Hirsch 1981). The prevalence of negative symptoms and the prevalence of Depression in Schizophrenia may vary depending on the way these symptoms are clinically considered and recognised. A recent survey reports that clinicians prescribe antidepressants to $30 \%$ of inpatients and $43 \%$ of outpatients with co-morbid schizophrenia and depression at all ages (Kasckow \& Zisook 2008). Same authors report that prevalence of such comorbidity may vary and ranges from 20 to $70 \%$ and, in their own study, ranges from 6 to 75\% (Häfner et al. 2002). Moreover, depressive symptoms are often recognized as the earliest and most frequent signs of impending schizophrenia (Häfner et al. 2002, An der Heiden et al. 2005, Addington et al. 1998, Koreen et al.1993, Chemerinski et al. 2008).

Depressive symptoms are also associated with higher impairment in social and vocational functioning, poor quality of life and an increased risk of relapse (Tollefson \& Andersen 1999), contributing to the alarmingly high rates of suicide in patients with schizophrenia (Moller 2008, Muller et al. 2001). It is of note that depressive mood as well as loss of self-confidence, feelings of guilt and suicidal thoughts are prevalent symptoms in patients admitted for the first time for the exacerbation of their psychosis (An der Heiden et al. 2005, Jin et al. 2001). However, despite the clinical 
interest on depression among schizophrenia patients, research studies explicitly examining depressive symptoms and their association with other psychopathological and clinical characteristics in psychotic patients are scarce (Jin et al. 2001, Conley et al. 2007). In addition, previous studies vary considerably in terms of their methodology of assessment, interval of observation or patients selection (Siris 2000) with some limitations on the generalizability of the results. The evaluation and diagnosis of depression in schizophrenia patients is furthermore complicated by the fact that some depressive symptoms such as sleep disturbances, lack in concentration, etc., can affect help-seeking and clinical ratings (Spellmann et al. 2017, Bener et al. 2011, 2012a,b, 2015, 2016a, Ghuloum et al. 2014). In addition, consanguinity has been shown to be clearly associated with an increased risk of genetically complex disorders (Bener et al. 2012a,b, 2016b, Ghuloum et al. 2014, Bittles 2013).

The aim of this study was to describe the co-morbidity between Major Depressive Disorder (MDD) and Schizophrenia (SZ) and compare clinical characteristics of MDD patients with versus without co-morbid SZ and to contribute to the understanding of the role of depressive symptoms in Schizophrenia patients as well as psychotic symptoms in MDD.

\section{SUBJECTS AND METHODS}

This is a cohort-study including patients from Qatar with age ranging 18- 65 years old and interviewed from March 2011 to June 2014, who consecutively attended the Department of Psychiatry at Rumeilah Hospital. All psychiatric diagnoses met the ICD-10 (International Classification of Diseases) criteria and were based on the Arabic World Mental Health - Composite International Diagnostic Interview (WMH-CIDI version 3.0; Kessler et al. 2004a, Kessler et al. 2004b). Paper and Pencil Personal Interview (PAPI) - version 6 has been employed to bridge the data into the BLAISE software (a computer-assisted interviewing) (Bener et al. 2012a,b, 2016b, Ghuloum et al. 2014, Bittles 2013, Kessler et al. 2004 a,b).

600 Qatari patients affected by Major Depression and Schizophrenia were approached; 396 (73.3\%) agreed to be assessed and were interviewed using the Arabic World Mental Health - Composite International Diagnostic Interview (WMH-CIDI version 3.0) validated by the Institute for Development, Research, Advocacy and Applied Care (IDRAAC) centre in Lebanon (Kessler et al. 2004a,b). 204 subjects did not agree to be interviewed showing no personal interest in the current study. Additionally, we employed the rating scale by American Psychiatric Association (2015), structured clinical interview for DSM-5 (SCID-5). The WMH-CIDI instrument in Arabic language was administered by well trained interviewers under supervision of the co-investigators (EED and MTAS). After the diagnostic assessment, all patients were rated employing the following instruments:

- Hamilton Depression Rating Scale and (HAM-D) (Hamilton 1967);

- Young Mania Rating Scale (YMRS) (Young et al. 2000);

- Beck Depression Inventory (BDI) (Beck et al. 1988) Depression was considered to be present if BDI score was greater than 10 .

Socio-demographics, medical and family history were collected using a validated self-administered questionnaire with the help of clinicians and trained nurses. A good inter-rater reliability, test-retest reliability and validity for almost all diagnostic categories have been tested for the CIDI. Cronbach's alpha was 0.89 and 0.90 upon test and retest, respectively, which proved good internal consistency. The mean kappa value was 0.87 , indicating a high level of reproducibility.

Institutional Review Board approval has been obtained from Weill Cornell Medical College and Hamad Medical Corporation for conducting this research in Qatar.

\section{Statistical Analysis}

Data were entered and analyzed with the Statistical Packages for Social Sciences [SPSS], Window version No.22. Frequency distributions, one and two-way tabulations were obtained. Student-t test was used to ascertain the significance of differences between mean values of two continuous variables and confirmed by non-parametric Mann-Whitney test. Chi-square analysis was performed to test for differences in proportions of categorical variables between two or more groups. In $2 \times 2$ tables, the Fisher's exact test (two-tailed) replaced the chi-square test if the assumptions underlying chisquare violated, namely in case of small sample size and where the expected frequency is less than 5 in any of the cells. Findings are considered statistically significant with a two-tailed value less than 0.01 , to compensate for multiple comparisons.

\section{RESULTS}

396 subjects (over 600) were recruited for the study and interviewed. $141 / 396$ (35.6\%) reported co-morbid $\mathrm{MDD} / \mathrm{SZ}$.

MDD with SZ were $42.69 \pm 14.33$ years old whereas MDD patients without SZ aged 41.59 \pm 13.59 . Sociodemographics of MDD patients with Schizophrenia vs MDD without SZ are shown in Table 1.

Statistically significant differences between patients affected by MDD with SZ and MDD without SZ were: higher BMI (Body Mass Index) $(\mathrm{p}=0.025)$, lower family income $(p=0.004)$, higher rate of cigarette smoking $(p<0.001)$, and higher level of consanguinity $(p=0.023)$. The rate of consanguinity among MDD with SZ patients was $31.9 \%(95 \% \mathrm{CI}=29.0-34.6)$. 
Table 1. Socio-demographic characteristics of Major Depressive Disorder with/without Schizophrenia (N=396) patients

\begin{tabular}{|c|c|c|c|}
\hline Variables & $\begin{array}{c}\text { MDD with Schizophrenia } \\
n=141 ;(\%)\end{array}$ & $\begin{array}{l}\text { MDD without Schizophrenia } \\
n=255 ;(\%)\end{array}$ & $p$-value \\
\hline Age groups & & & 0.905 \\
\hline$<34$ years & $44(31.2)$ & $79(31.0)$ & \\
\hline $35-49$ year & $52(36.9)$ & $101(39.6)$ & \\
\hline $50-64$ years & $27(19.1)$ & $48(18.8)$ & \\
\hline$>65$ years & $18(12.8)$ & $27(10.6)$ & \\
\hline Gender & & & 0.131 \\
\hline Males & $52(26.9)$ & $114(44.7)$ & \\
\hline Females & $89(63.1)$ & $141(55.3)$ & \\
\hline BMI Group & & & 0.025 \\
\hline Normal $\left(<25 \mathrm{~kg} / \mathrm{m}^{2}\right)$ & $37(26.2)$ & $96(37.6)$ & \\
\hline Overweight (26-39) & $53(37.6)$ & $95(37.3)$ & \\
\hline Obese $(30+)$ & $51(36.2)$ & $64(25.1)$ & \\
\hline Marital Status & & & 0.241 \\
\hline Single & $24(17.0)$ & $56(22.0)$ & \\
\hline Married & $117(83.0)$ & $199(78.0)$ & \\
\hline Education Level & & & 0.281 \\
\hline Primary & $19(13.5$ & $48(18.8)$ & \\
\hline Intermediate & $37(26.2)$ & $48(18.8)$ & \\
\hline Secondary & $46(32.6)$ & $89(345.9)$ & \\
\hline University & $39(27.7)$ & $70(27.5)$ & \\
\hline Occupation & & & 0.554 \\
\hline Housewife & $20(14.2)$ & $50(19.6)$ & \\
\hline Sedentary/Professional & $48(34.0)$ & $93(36.54)$ & \\
\hline Manual & $41(29.1)$ & $66(25.9)$ & \\
\hline Business man & $12(8.5)$ & $18(7.1)$ & \\
\hline Army/police & $20(14.2)$ & $28(11.0)$ & \\
\hline Household income/month & & & 0.004 \\
\hline$<\$ 3,000$ & $37(26.2)$ & $99(38.8)$ & \\
\hline$\$ 3,000-\$ 5,000$ & $60(42.6)$ & $69(27.1)$ & \\
\hline$>\$ 5,000$ & $44(31.2)$ & $87(34.1)$ & \\
\hline Cigarette smoking & & & $<0.001$ \\
\hline Never & $105(74.5)$ & $233(91.4)$ & \\
\hline Current & $21(14.8)$ & $16(6.3)$ & \\
\hline Past & $15(10.6)$ & $6(2.4)$ & \\
\hline Consanguinity & & & 0.023 \\
\hline Yes & $45(31.9)$ & $55(21.6)$ & \\
\hline No & $96(68.1)$ & $200(78.4)$ & \\
\hline
\end{tabular}

MDD: Major Depression Disorder; SZ: Schizophrenia

Table 2 shows the prevalence and clinical characteristics of MDD with and without SZ. Significant differences were found in General Health Score $(p=0.017)$, Clinical Global Impression-BD Score $(p=0.042)$, duration of illnesses $(\mathrm{p}=0.003)$, and Global Assessment of Functioning $(\mathrm{p}=0.012)$, as shown. Rates of anxiety dimensions (e.g.: general anxiety, agoraphobia, somatisation, etc.), mood dimensions (major depression, mania, oppositional defiant behaviour, Bipolar disorder), Attention Deficit Hyperactivity Disorder, psychotic and personality dimensions were higher among MDD with SZ patients than MDD without SZ.
Figure 1 illustrates the Venn Diagram showing the overlapping prevalence of MDD with/without SZ and consanguinity/family history.

\section{DISCUSSION}

The aim of the current study was to explore the prevalence of comorbidity between MDD and SZ and compare clinical features of MDD patients with and without SZ. Co-morbidity between MDD and SZ is relatively common (Bartels \& Drake 1988, Kasckow \& Zisook 2008, An der Heiden et al. 2016, Bener et al. 2018). 
Table 2. Clinical characteristics of Major Depressive Disorder with/without Schizophrenia (N=396) patients

\begin{tabular}{|c|c|c|c|}
\hline Clinical Characteristics & $\begin{array}{c}\text { MDD with } \\
\text { Schizophrenia } \mathrm{n}=141 \\
\text { Mean } \pm \text { SD }\end{array}$ & $\begin{array}{c}\text { MDD without } \\
\text { Schizophrenia } \mathrm{n}=255 \\
\text { Mean } \pm \text { SD }\end{array}$ & $p$-value \\
\hline Age at onset of illness & $42.10 \pm 12.80$ & $41.75 \pm 12.40$ & 0.795 \\
\hline Duration of illness( years) & $9.34 \pm 3.31$ & $10.47 \pm 3.84$ & 0.003 \\
\hline No. of visits/ Hospitalizations & $3.00 \pm 1.58$ & $2.75 \pm 1.62$ & 0.419 \\
\hline General Health Questionnaire Score & $15.00 \pm 7.32$ & $16.20 \pm 6.63$ & 0.017 \\
\hline Hamilton Depression rating Score & $3.64 \pm 0.56$ & $3.70 \pm 0.51$ & 0.061 \\
\hline Young Mania Rating scale-YMRS Score. & $34.23 \pm 5.26$ & $34.75 \pm 5.48$ & 0.443 \\
\hline Clinical Global impression Score & $4.80 \pm 0.76$ & $4.30 \pm 0.60$ & 0.042 \\
\hline Global Assessment of Functioning & $38.04 \pm 6.36$ & $36.65 \pm 5.52$ & 0.010 \\
\hline Anxiety Dimensions at DSM-5 (SCID-5) ${ }^{*}$ & $\mathrm{n}(\%)$ & $\mathrm{n}(\%)$ & p-value \\
\hline Generalized Anxiety Disorders & $35(24.8)$ & $33(12.9)$ & 0.003 \\
\hline Panic Disorder & $28(19.9)$ & $24(8.4)$ & 0.005 \\
\hline Agoraphobia without panic & $25(17.7)$ & $23(9.10)$ & 0.011 \\
\hline Specific Phobia & $10(7.1)$ & $19(7.5)$ & 0.8966 \\
\hline Social Phobia & $22(15.6)$ & $31(12.2)$ & 0.335 \\
\hline Post Traumatic stress Disorder & $21(14.9)$ & $32(12.5)$ & 0.512 \\
\hline Separation Anxiety Disorders & $35(24.8)$ & $27(10.6)$ & 0.001 \\
\hline Somatization disorder & $29(20.6)$ & $23(9.10)$ & 0.001 \\
\hline Any Anxiety Disorders & $39(26.7)$ & $24(12.6)$ & 0.002 \\
\hline \multicolumn{4}{|l|}{ Mood Dimensions at DSM-5 (SCID-5) ${ }^{*}$} \\
\hline Major Depression Disorders & $32(22.7)$ & $26(10.2)$ & 0.001 \\
\hline Dysthymia & $26(18.4)$ & $29(11.4)$ & 0.050 \\
\hline Mania & $34(24.1)$ & $30(10.2)$ & 0.001 \\
\hline Bipolar Disorder & $22(15.6)$ & $19(6.5)$ & 0.003 \\
\hline Any Mood Disorders & $41(29.0)$ & $44(17.3)$ & 0.030 \\
\hline Oppositional Defiant Disorder & $21(14.9)$ & $33(11.2)$ & 0.560 \\
\hline Attention Deficit Hyperactivity (ADHD) & $34(24.1)$ & $39(15.3$ & 0.030 \\
\hline Psychotic dimensions at DSM-5 (SCID-5) ${ }^{*}$ & $28(19.9)$ & $29(11.4)$ & 0.025 \\
\hline Personality traits dimension at DSM-5 (SCID-5) ${ }^{*}$ & $26(18.4)$ & $26(10.2)$ & 0.020 \\
\hline
\end{tabular}

* American Psychiatric Association. (2015). Structured Clinical Interview for DSM-5 (SCID-5)

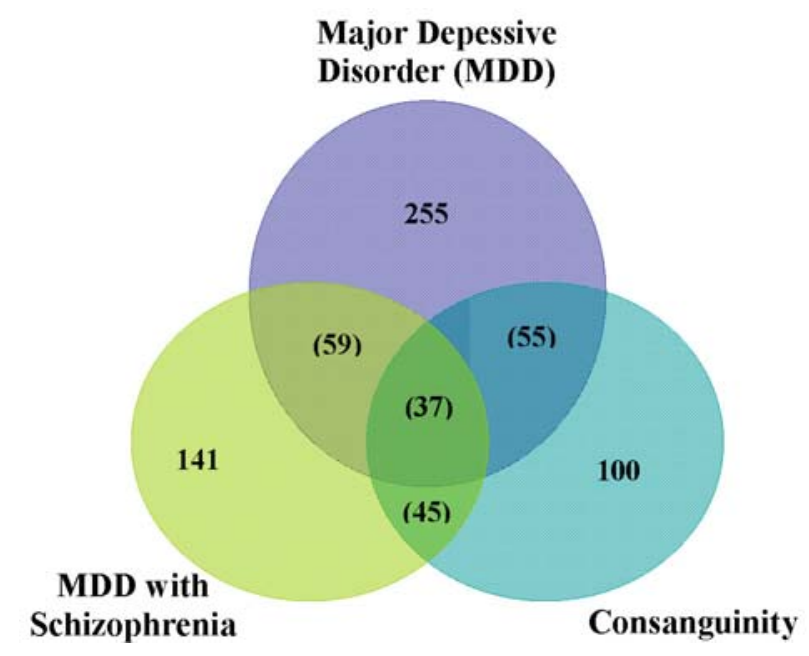

Figure 1. Venn Diagram showing the overlapping Prevalence of Major Depressive Disorder with/without Schizophrenia and consanguinity $(\mathrm{N}=396)$

In our study the rate of co-morbidity was $35.60 \%$ which appears consistent with previous studies reporting 30\% of inpatients and $43 \%$ of outpatients with schizophrenia and depression at all ages (Bartels \& Drake 1988).
As suggested by Schennach et al. (2015), depressive symptoms may be considered as a distinct psychopathological domain in patients suffering from schizophrenia and our study seems to confirm this evidence since comorbidity between MDD and SZ reported specific different clinical characteristics (as shown). Moreover, a recent study investigated the application and comparison of common remission and recovery criteria between patients with schizophrenia and major depressive disorder reporting that functional remission and recovery rates were significantly lower in schizophrenia than in depressive patients at the one-year follow-up (Spellmann et al. 2017).

Although the co-occurrence of SZ and MDD is a common and challenging co-morbid condition, the relationship between SZ and MDD has remained unclear (Bener et al. 2018). Even if this condition is underrecognized in clinical practice, it may significantly change the illness presentation and its outcome as shown by the clinical differences reported in our study.

In addition it appears that in general, consanguinity increases the risk of mental illness. Bener and colleagues $(2016 \mathrm{a}, \mathrm{b})$ found that subjects from consanguineous parents report a significantly higher risk to develop a 
mental disorders. Bener et al. (2015, 2016b, 2018) have reported that rates of major depression, bipolar disorder were significantly higher in consanguineous marriages than in non-consanguineous ones as well as having an impact on the onset of symptoms. This study confirms a higher level of consanguinity among patients reporting MDD and SZ comorbidity.

\section{CONCLUSIONS}

In conclusion, this study has shown that MDD-SZ is a common clinical co-morbidity, largely under-recognized in clinical practice, which may significantly change the illness presentation and outcome. Also, prevalence of MDD with SZ was higher among patients reporting a degree of consanguinity.

\section{Acknowledgements:}

This study was generously supported and funded by the Qatar Diabetes Association, Qatar Foundation and partially Qatar National Research Fund- QNRF NPRP 30-6-7-38. The authors would like to thank the Hamad Medical Corporation for their support and ethical approval (HMC RP \# 11187/11).

\section{Conflict of interest: None to declare.}

\section{Contribution of individual authors:}

Abdulbari Bener designed and supervised the study and was involved in data collection, statistical analysis, the writing of the paper.

Elnour E. Dafeeah \& Mohammed T. Abou-Saleh were involved in data collection, interpretation of data and writing manuscript.

Dinesh Bhugra \& Antonio Ventriglio were involved in the interpretation of data and in writing the manuscript.

All authors approved the final version.

\section{References}

1. Addington D, Addington J, Patten S: Depression in people with first-episode schizophrenia. Br J Psychiatry 1998; 172:90-92

2. American Psychiatric Association. Structured clinical interview for DSM-5 (SCID-5): Retrieved from http://www.appi.org/products/structured-clinicalinterview-for-DSM-5 and SCID-5; 2015

3. An der Heiden W, Könnecke R, Maurer K, Ropeter D, Häfner H: Depression in the long-term course of schizophrenia. Eur Arch Psychiatry Clin Neurosci 2005; 255:174-184

4. An der Heiden W, Leber A, Häfner H: Negative symptoms and their association with depressive symptoms in the long-term course of schizophrenia. Eur Arch Psychiatry Clin Neurosci 2016; 266:387-396
5. Bartels SJ \& Drake RE: Depressive symptoms in schizophrenia: comprehensive differential diagnosis. Compr Psychiatry 1988; 29:467-483

6. Beck A, Steer R, Carbin M: Psychometric properties of the Beck Depression Inventory: Twenty-five years of evaluation. Clin Psychol Rev 1988; 8:77-100

7. Bener A, Abou-Saleh MT, Dafeeah EE, Al Abdulla M, Ventriglio A: The prevalence of co-morbid obsessivecompulsive disorder and bipolar disorder in highly endogamous population: which came first. IJCMH 2016a; 9:407-413

8. Bener A, Abou-Saleh MT, Dafeeah EE, Bhugra, D: The prevalence, size and burden of psychiatric disorders at the Primary Health Care visits in Qatar: Too little time. J Family Med Primary Care 2015; 4:89-95

9. Bener A, Abou-Saleh MT, Mohammad RM, Dafeeah EE, Ventriglio A, Bhugra D: Does consanguinity increase the risk of mental ilnesses? A population-based study. Int J Culture Mental Health 2016b; 28:172-181

10. Bener A, Dafeeah EE \& Samson N: The Impact of Consanguinity on Risk of Schizophrenia. J Psychopathology 2012b; 45:399-400

11. Bener A, Dafeeah EE, \& Samson N: Does consanguinity increase the risk of schizophrenia? Study on primary health care center visits. Ment Health Fam Med 2012a; 9:241-248

12. Bener A, Dafeeah EE, Abou-Saleh MT, Bhugra D, Ventriglio A: Schizophrenia and co-morbid obsessive-compulsive disorder: Clinicalcharacteristics. Asian J Psychiatry 2018; 37:80-8

13. Bener A, Ghuloum $S$ \& Abou-Saleh MT: Prevalence, symptom pattern and co-morbidity of anxiety and depressive disorders in primary care in Qatar. Soc Psych Psychiatric Epid 2011; 57:480-486

14. Bittles AH: Genetics and global health care. J $R$ Coll Physicians Edinb 2013; 43:7-10

15. Chemerinski E, Bowie C, Anderson H, Harvey PD: Depression in schizophrenia: methodologicalartifact or distinct feature of the illness? J Neuropsychiatry Clin Neurosci 2008; 20:431-40

16. Conley RR, Scher-Svanum H, Zhu B, Faries DE, Kinon $B J$ : The burden ofdepressive symptoms in the long-term treatment of patients with schizophrenia. Schizophr Res 2007; 90:186-97

17. Ghuloum S, Bener A, Dafeeah EE, Zakareia AE, El-Amin A, El-Yazidi T: Prevalence of Common Mental Disorders in General Practice attendees: Using World Health Organization Composite International Diagnostic Interview (WHO-CIDI) in Qatar. Int $J$ Clin Psychiatry Ment Health 2014; 2:38-46

18. Häfner $H$, Maurer $K$, Löffler $W$, an der Heiden $W$, Könnecke R, Hambrecht $M$ : The early course of schizophrenia. In: Häfner $H$ (ed) Risk and protective factors in schizophrenia. Towards a conceptual model of the disease process. Steinkopff Verlag, Darmstadt, 2002; pp 207-228

19. Hamilton M: Development of a rating scale for primary depressive illness. Brit J Clin Psych 1967; 6: 278-296

20. Jin H, Zisook S, Palmer BW, Patterson TL, Heaton RK, Jeste DV: Association of depressive symptoms with worse functioning in schizophrenia: a study in older outpatients. J Clin Psychiatry 2001; 62:797-803 
21. Kasckow JW \& Zisook S: Co-Occurring Depressive Symptoms in the Older Patient with Schizophrenia. Drugs Aging 2008; 25:631-647

22. Kessler RC \& Ustun TB: The World Mental Health (WMH) survey initiative version of the World Health Organization (WHO) Composite International Diagnostic Interview (CIDI). Int J Methods Psychiatr Res 2004b; 13:93-121

23. Kessler RC, Abelson J, Demler O, Escobar JI, Gibbon M, Guyer ME et al: Clinical calibration of DSM-IV diagnoses in the World Mental Health (WMH) version of the World Health Organization (WHO) Composite International Diagnostic Interview (WMH-CIDI). Int $J$ Methods Psychiatr Res 2004a; 13:122-39

24. Knights $A \&$ \& Hirsch SR: "Revealed" Depression and drug treatment for schizophrenia. Arch Gen Psychiatry 1981, 38:806-11

25. Koreen AR, Siris SG, Chakos M, Alvir J, Mayerhoff D, Lieberman J: Depression in first-episode schizophrenia. Am J Psychiatry 1993; 150:1643-1648

26. Moller HJ: Drug treatment of depressive symptoms in schizophrenia. Clin Schizophr Relat Psychoses 2008; 1:328-40.24

27. Muller MJ, Szegedi A, Wetzel H, Benkert O: Depressive factors and their relationships with other symptom domains in schizophrenia, schizoaffective disorder, and psychotic depression. Schizophr Bull 2001; 27:19-28

28. Schennach R, Riedel M, Obermeier M, Seemüller F, Jäger $M$, Schmauss $M$, et al.: What are depressive symptoms in acutely ill patients with schizophrenia spectrum disorder? Eur Psychiatry 2015; 30:43-50

29. Siris $S G \&$ Bench $C$ : Depression and schizophrenia. In: Hirsch SR, Weinberger DR (eds) Schizophrenia, 2nd edn. Blackwell Publishing, Oxford, 2003; pp 142-167

30. Siris SG: Depression in schizophrenia: perspective in the era of ,Atypical" antipsychotic agents. Am J Psychiatry 2000; 157:1379-89

31. Spellmann I, Schennach R, Seemüller F, Meyer S, Musil R, Jäger $M$, et al.: Validity of remission and recovery criteria for schizophrenia and major depression: comparison of the results of two one-year follow-up naturalistic studies. Eur Arch Psychiatry Clin Neurosci 2017; 267:303-313

32. Tollefson GD \& Andersen SW: Should we consider mood disturbance in schizophrenia as an important determinant of quality of life? J Clin Psychiatry 1999; 60(Suppl. 5):23-9

33. Young RC, Biggs JT, Ziegler VE, Meyer DA: Young Mania Rating Scale. In: Handbook of Psychiatric Measures. Washington, DC: Am Psych Assoc 2000; 540-542

\section{Correspondence:}

Prof. Abdulbari Bener; MD, Advisor to WHO

Department of Biostatistics \& Medical Informatics, Cerrahpaşa Faculty of Medicine, Istanbul University Cerrahpaşa and Istanbul Medipol University, International School of Medicine 34098 Cerrahpasa-Istanbul, Turkey

E-mail: abdulbari.bener@istanbul.edu.tr,abener99@yahoo.com 